\title{
Tone in Bodish languages: Typological and sociolinguistic contributions
}

\author{
Kristine A. Hildebrandt
}

\section{Introduction: The challenge of Bodish prosodic systems}

The prosodic systems of Bodish Tibeto-Burman (TB) languages of Nepal present many challenges to our understanding of the phonological profiles of Sino-Tibetan (ST) languages, and to languages of South and Southeast Asia in general. ${ }^{1}$ This paper aims to highlight some interesting suprasegmental properties in several Bodish languages, and the ways that tone and the Tone Bearing Unit (TBU) in these languages contribute to their location in a typologically distinct sub-area between greater South and Southeast Asia. The proposed location of Bodish languages in a "buffer zone" (cf. Stilo 2005 for Northwest Iran as a typological buffer zone between Arabic-type and Indic-type areas) is not new here; rather, this account gives additional, phonological, evidence for such a proposal.

At the same time, a deeper understanding of Bodish prosodic properties is complicated by sociolinguistic variables affecting the realization of tone, including gender, bilingual contact, and formal education. Therefore, another aim of this paper is to synthesize the ways in which these sociolinguistic variables have enriched previous studies, and how an optimal account of a language's phonology is one that recognizes how synchronic sub-systems and mechanisms of diachronic change align with different components of the speaker community.

The organization of this paper reflects the diversity of the goals. In Section 2 I provide an overview of the tonal properties of a number of Bodish TB languages of Nepal and how these properties necessarily complicate an idea of mainly syllabic tone systems in ST languages. This point is elaborated on in Section 3, where I show in two surveys that the type and domain of tone systems of the Bodish (and other TB) languages, located along the Himalayan range of Nepal, India and Bhutan, provide additional evidence for typological enclave effects (cf. Bickel and Nichols 2003). In Section 4 I turn to the complex variation inherent in these systems, where- 
by the parameters to tone in Bodish languages have different realizations according to different socio-cultural factors.

\section{Tone and the phonological word in Bodish languages}

As noted by Matisoff (1999) the topic of Sino-Tibetan tonology is too vast to be adequately summarized in a single account. It is important to belabor the point here, however, that once the focus is shifted away from the prototypical "omnisyllabic" nature of Sinitic languages, the tone profiles begin to take on intriguingly different and complex dimensions.

\subsection{Tone in Sinitic and in Tibeto-Burman languages}

Despite the wide variety of tone profiles within the family, a popular assumption in literature is that the TBU in ST languages is the syllable. Moira Yip's 2002 survey of Asian (including ST) tone systems focuses almost exclusively on monosyllabic languages like Mandarin and Cantonese, with brief mention of other monosyllabic TB languages like Bai and Jingpho. While there is some discussion of Lhasa Tibetan tone with its additional phonation correlates, and also mention of word-tone in languages of Papua New Guinea, the received perception is of an overall syllabic TBU profile of ST and TB languages.

It is in fact true that a monosyllabic tone profile fits for many ST languages of Southeast Asia. Morphemes (lexical and grammatical) are largely monosyllabic, and many phonological processes make exclusive reference to individual syllables (cf. Matisoff 1973b; 1995; 1999). Lahu (Lolo-Burmese) is a textbook case of this, with potentially long combinations of mono-syllabic morphemes bearing individual, underlying tone properties: "The Lahu tones do not exhibit any strictly automatic, phonologically conditioned sandhi-behavior." (Matisoff 1973a: 27). This is illustrated in (1) (data from Matisoff 1973a: 454).

(1) Lahu (Sino-Tibetan, Lolo-Burmese)

$\begin{array}{lllll}\check{S} \dot{i} & e & \text { thâ } & \text { gà } & q o^{2} \\ \text { die } & \text { PTCL } & \text { when } & \text { arrive } & \text { TOP } \\ \text { 'If [the time to] die arrives...' }\end{array}$

'If [the time to] die arrives...' 
In fact, in Lahu there is only a single case of tone alternation between adjacent syllable-morphemes: tone lowering on certain property concept

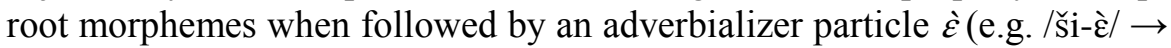
[ší.̀े] 'yellow-ly') (1973a: 30). Thus, the strictly syllabic TBU obscures any notion of word as prosodically distinct from the syllable.

But, as Yip (2002: 172-173) duly notes, words (in a grammatical sense) in Southeast Asian languages can be polysyllabic, frequently formed via compounding. In Sinitic languages in particular, morpheme concatenations may undergo various tonal changes. But even in tone sandhi environments, the general idea is that a word-level pattern is the result of changes to at least one syllable with an otherwise underlying, contrastive tone.

Beyond the profile characteristic of Southeast Asian languages, we may also find TB languages (largely) west of the Himalayan plateau to be either a-tonal (e.g. Himalayish languages and some Tibetan 'dialects'), or 'marginally/incipiently tonal', where tone is a combination of two or more phonetic properties like vowel $\mathrm{F}_{0}$ and consonant or vowel laryngeal settings (i.e. phonation types) (cf. Stephen Watters 1999 and 2002 for studies of several Tibetan-type languages).

Kyirong Tibetan is an example of this second type. It has six phonemic tones and resembles Sinitic type systems by virtue of polytonicity. However, this system is complex in that vowel $F_{0}$ is only one of a number of relevant correlates, summarized in Table $1 .{ }^{3}$

Table 1. Kyirong Tibetan tones (Huber 2000: 22-24)

\begin{tabular}{|c|c|c|}
\hline Registers & Correlates & Cases \\
\hline High Level & Modal; voiceless asp. & $t^{h} \bar{O}$ 'list'; tō 'food' \\
\hline High Falling & Modal/Creaky; voiceless asp. & $t_{\epsilon}{ }^{h} \grave{D}^{\prime}$ 'religion'; tù:' 'stir' \\
\hline Mid Level & Modal; \pm voiced & to 'two'; $d \underline{o}$ 'lower valley' \\
\hline Mid Falling & Modal/Creaky; \pm voiced & tô:' 'heat'; $d z \hat{o}:$ 'magazine' \\
\hline Low Level & Breathy; \pm voiced & 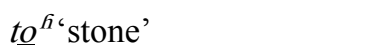 \\
\hline Low Falling & Breathy; \pm voiced & $t \hat{y}_{:}{ }^{h}$ 'evil spirit' \\
\hline
\end{tabular}

There are additional correlates of vowel phonation found across the three registers: Vowel phonation (modal, breathy and occasionally creaky for contour tones), and onset (obstruent) phonation for consonants.

While it is shown in Section 2.2 that Bodish languages may be typed as marginally tonal due to multiple phonation types, the domain of the TBU also makes them of special typological interest in this account. 


\subsection{Bodish tone and the phonological word}

Figure 1 shows the genetic sub-grouping of the Tibeto-Burman sub-family:
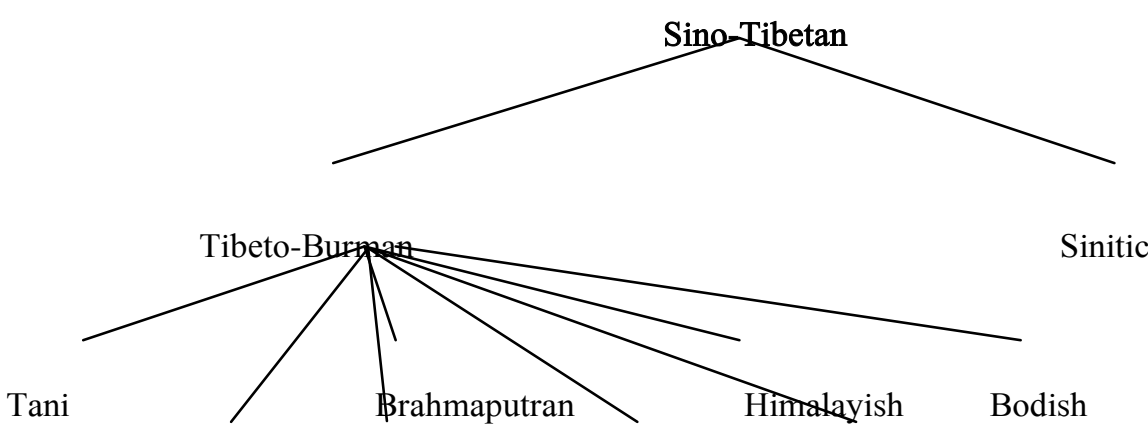

Qiangic Kuki-Chin Karenic Lolo-Burmese

Figure 1. Sub-Grouping of Sino-Tibetan and Tibeto-Burman

The Bodish sub-grouping includes Tamangic languages and the Tibetan 'dialects'. Tamangic languages include Tamang, Gurung, Thakali, Manange, Nar-Phu, Chantyal, Kaike and Seke/Tangbe, displayed in Map $1 .^{4}$

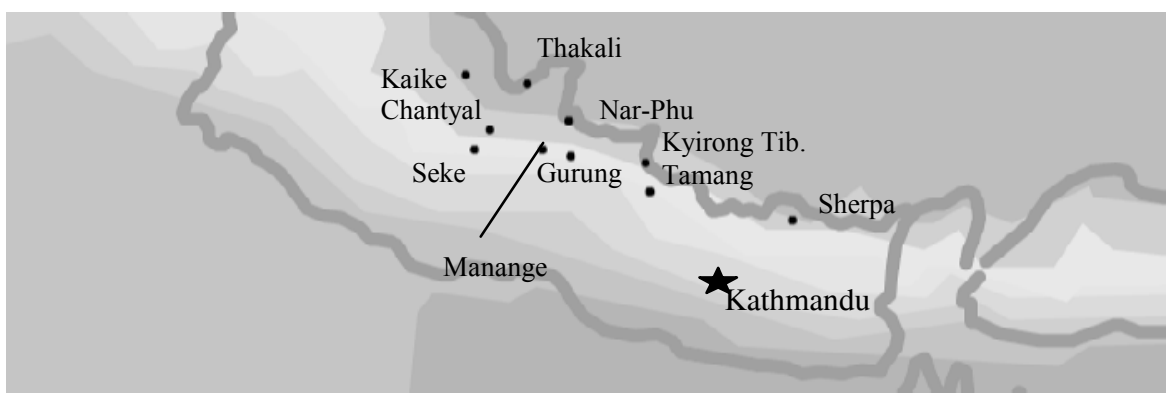

Map 1. Geographic Location of Selected Bodish Languages

These languages complicate an otherwise perceived binary typological opposition within the family (i.e. tonal or a-tonal/marginally tonal, with a syllabic TBU). For a number of Bodish (and also Kuki-Chin) languages of the Nepal Himalaya (specifically, those languages surrounded by the Brahmaputra river, which runs through the Kailash range, through southwest Tibet to the Ganges in India), the TBU expands in complex and interesting ways. I now provide a brief description of three Bodish (Tamangic) lan- 
guages and how their representative tone profiles expand the notion of the TBU, revealing the relevance of the phonological word in ST languages.

\subsubsection{Tamang}

An early and in-depth account of Bodish tone par excellence is found in Mazaudon (1973), with a phonological and phonetic description of (Risiangku) Tamang tone. The phonetic realization of the four tones is the 'phonological word', with the same patterns of pitch correlates on monosyllabic words also found on polysyllabic words, regardless of morphological composition or lexical class. Tamang has four tones that are different in pitch height (high and low) and in pitch contour (level and falling). In addition, there is a voice quality difference for the two heights: The high tones have modal vowels and the low tones have breathy vowels (Mazaudon 1973: 82), illustrated in Table 2.

Table 2. Tamang tones (Adapted from Mazaudon 1973: 94-98)

\begin{tabular}{lll}
\hline Tone & Correlates & Case \\
\hline$/ 1 /$ & High Falling, Modal & $t \int^{h} i$ 'exclamation of dislike' \\
$/ 2 /$ & High Level, Modal & $t \int^{h} i$ 'grass' \\
$/ 3 /$ & Low Level, Breathy & $t f j:$ ' 'grip' \\
$/ 4 /$ & Low-Rising, Breathy & $t f j:$ ' 'think, remember' \\
\hline
\end{tabular}

In Mazaudon's phonetic account of the tones in different syllable structures and phrase types, she shows that Tamang is a word-tone language; the pitch properties of the tones carry across the stem, including bound 'grammatical morphemes' (i.e. suffixes). ${ }^{5}$ Because suffixes are inherently a-tonal and pick up the pitch properties of a preceding syllable, it is possible that two morphologically distinct, but segmentally identical suffixes, when occurring with roots that are also both segmentally and tonally homophonic, are (without appropriate context), indistinguishable to Tamang speakers, shown in example (2) (1973: 70).

(2) $/{ }^{2}$ ta $=$ ri $/$ axe $=$ INDEF 'an axe' vs. $/{ }^{2}$ ta $=$ ri $/$ horse $=$ LOC 'on the horse' 2.2.2. Gurung

This summary of Kaski Gurung (Ghachok, Nepal) is synthesized from several accounts: Glover (1970), Glover et al. (1977), Glover and Landon 
(1980), Hale (1973), Mazaudon (1978), Sprigg (1997). The system is essentially the same as with Tamang, where tone is based on vowel phonation type (i.e. "register" in accounts of Gurung), and vowel $\mathrm{F}_{0}$ (i.e. "accent"). The correlates are linked; breathy vowels associate with low $\mathrm{F}_{0}$, and modal vowels associate with high $\mathrm{F}_{0}$. In addition, there is a similar consonant onset correspondence seen with Tamang. Voiced onset are found only with breathy vowels, while voiceless aspirated onsets are found only with modal vowels, giving rise to a four-way system, illustrated in Table 3.

Table 3. Gurung tones on monosyllabic roots (Mazaudon 1978: 175-178)

\begin{tabular}{lll}
\hline Tone & Correlates & Cases \\
\hline$/ 1 /$ & Modal, High and level & $p^{h} O$ 'deer' \\
$/ 2 /$ & Breathy, High Falling & $p^{h}$ o 'belly \\
$/ 3 /$ & Modal Low level/falling & $p o$ 'beer mash' \\
$/ 4 /$ & Breathy Low level/falling (or rise-fall) & $p o$ 'strength' \\
\hline
\end{tabular}

An initial analysis by Glover (1970) was that the domain for contrastive tone is the morpheme. However, Hale (1973) noted that a word will have maximally one accent, and vowel phonation is realized only on the initial syllable of a word, no matter the morphological complexity. Mazaudon (1978: 162) has also noted that disyllabic morphemes show the same pitch patterns as bimorphemic, polysyllabic combinations, as in Table 4.

Table 4. Tone patterns on Gurung stems (Adapted from Sprigg 1997: 451)

\begin{tabular}{|c|c|c|c|}
\hline$/ 1 /$ & $12 /$ & $13 /$ & /4/ \\
\hline fí-lá & $\int \hat{e}-1 \hat{a}$ & $t \int \hat{i}$-là & jộ-là \\
\hline 'die-PERF' & 'know-PERF' & 'bite-PERF' & 'steal-PERF' \\
\hline
\end{tabular}

Thus, as with Tamang, the phonological word (henceforth, P-word) in Gurung is the most appropriate TBU; it is a category that captures the necessary interplay between prosodic notions (e.g. syllable, foot) and morphological ones (e.g. root, stem, affix).

\subsubsection{Manange}

Tone in Manange is diachronically more phonologized than in other Bodish languages in that contrastive pitch is now the primary correlate to tone, and other correlates are secondary in that they do not apply for all of the 
tones (cf. Mazaudon 1977). In this sense, Manange is furthest along the tonogenetic pathway to becoming a 'pure', pitch-based tone language.

Manange has four tones aligning primarily along a parameter of contrastive vowel pitch. Figure 2 shows lines linking the starting, midpoint and endpoint mean $\mathrm{F}_{0}$ measurements taken from lexical items from the four tones (reproduced from Hildebrandt 2005: 26).

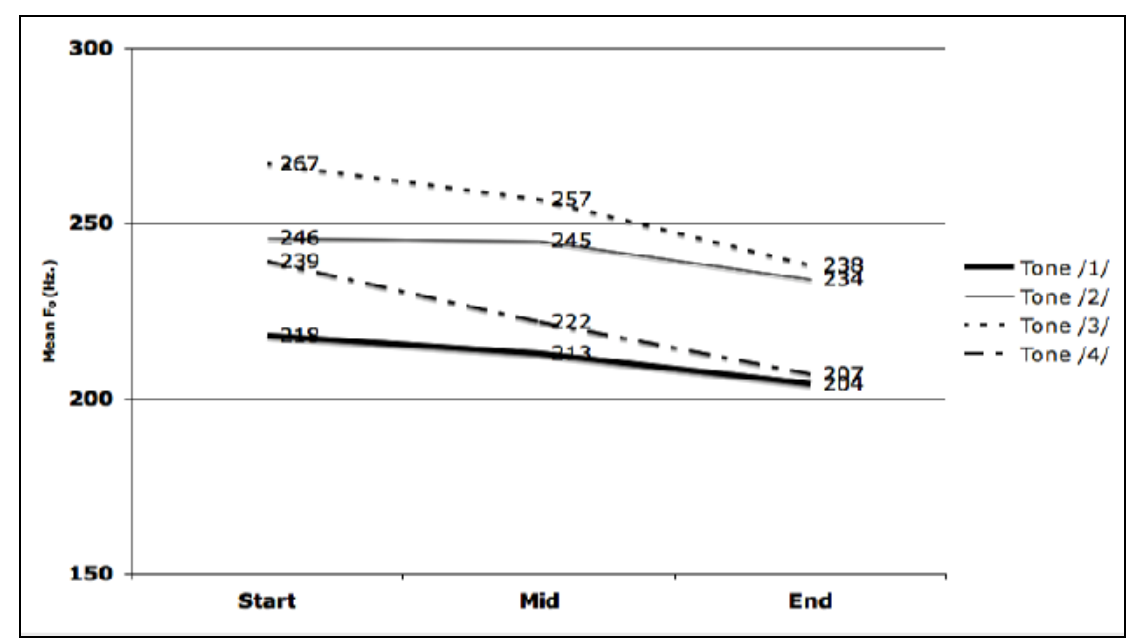

Figure 2. Mean $\mathrm{F}_{0}$ measurements, Four Tones, Manange

As with the other Bodish languages, there are two low tones and two high tones, with a further division into level and falling tones. Words with initial sonorant consonants are found in all four tones, and display the same pitch properties in all tones as do words with initial obstruents. For obstruent initials, there is a further parameter: Onset aspiration. As tokens in Table 5 show, the two contour tones (/3/ and /4/) are split for aspiration.

Only words with unaspirated obstruent onsets occur in tone $/ 3 /$, while only words with aspirated onsets occur in tone $/ 4 /$. This split is not observed for words with sonorant initials, such that $F_{0}$ is the primary tonal correlate. Aspiration distinctions have secondary significance, applying for obstruent-initial words in two tones. 
Table 5. Onset aspiration differences across tones (Hildebrandt 2003: 15)

\begin{tabular}{llllllll}
\hline \multicolumn{2}{c}{$/ \mathbf{1 /}$} & \multicolumn{2}{c}{$/ \mathbf{2}$} & \multicolumn{2}{c}{$/ \mathbf{3} /$} \\
\hline+ Asp & $-A s p$ & + Asp & - Asp & Asp & - Asp & + Asp & - Asp \\
\hline$p^{h} i$ & $p \tilde{\imath}$ & $p^{h} i$ & $p i$ & $\mathrm{n} / \mathrm{a}$ & $p i$ & $p^{h} l i$ & $\mathrm{n} / \mathrm{a}$ \\
'late' & 'give' & 'peel' & 'release' & & 'say' & 'four' & \\
$t^{h} \tilde{e}$ & $t e$ & $t^{h} \tilde{e}$ & $t e$ & $\mathrm{n} / \mathrm{a}$ & $t \tilde{e}$ & $t^{h} e$ & $\mathrm{n} / \mathrm{a}$ \\
'move' & 'dig' & 'stop' & 'remove' & & 'fasten' & 'pin' & \\
\hline
\end{tabular}

As with other Bodish languages, the TBU in Manange is the P-word, including the mono- or polysyllabic root or stem morpheme and bound affixes and clitics. So, a single pitch trajectory also spreads across morphologically complex P-words. Figure 3 shows lines for the (mean) starting, mid-point and ending $\mathrm{F}_{0}$ values of a near-minimal set of verbs, all with the nominalizing suffix $-p \wedge$ (reproduced from Hildebrandt 2005: 31 ).

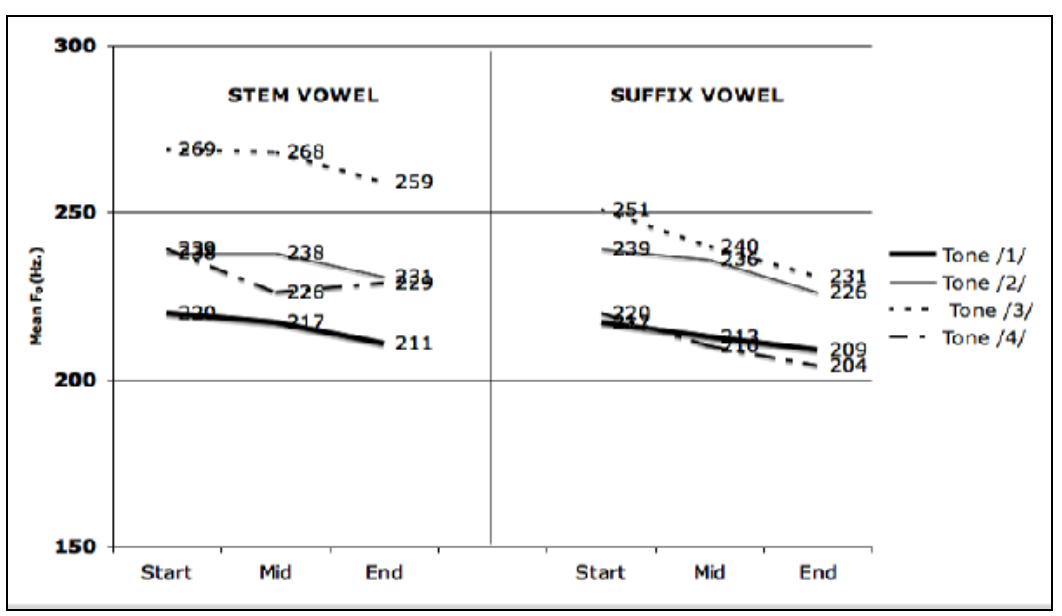

Figure 3. Mean $\mathrm{F}_{0}$ measurements, Verb Stem + Suffix, Manange

The $\mathrm{F}_{0}$ values spread from root across suffix syllables, indicating that phonologically bound grammatical morphemes are inherently toneless.

\subsection{Summary}

There are other word-tone Bodish languages, including Sherpa (Watters 1999; Kelly 2004), Seke/Tangbe (Honda 2002), Thakali (Georg 1996), and Nar-Phu (Noonan 2003). Other Bodish languages, like Kyirong Tibetan, 
are hybrid between word-tone and syllabic, with some morphemes as tonal, and others a-tonal (Huber 2002; Hall and Hildebrandt 2006). In addition, at least one non-Bodish language (Meithei, Kuki-Chin) has the P-word as the TBU.

Thus, even a qualitative survey of Bodish necessarily complicates the strictly syllabic view of Sino-Tibetan prosodic systems. A closer look at the nature of tone and the TBU shows that both Bodish, and languages from other TB sub-groupings located in the Himalayan region, stand apart from other related languages in this way.

\section{A crosslinguistic survey of tone types and tone domains}

This study concerns two hypotheses about the nature of tone in a set of Sino-Tibetan languages in a proposed sub-area straddling South and Southeast Asia. While the findings are most relevant to Bodish languages, a Himalayish language also identified as a Buffer Zone language (Kham) also shows similar tone properties. Therefore, the findings can at least preliminarily be extended beyond the more narrow genetic parameters to include geographic ones.

The idea that this sub-area is unique is inspired by Bickel and Hildebrandt (2005), who, following Stilo's (2005) terminology, propose 'buffer zone' status for languages from the central Himalayan region of the $\mathrm{Ne}$ $\mathrm{pal} /$ Tibet based on some features. A buffer zone is more specifically defined here as a geo-cultural area of mixed typology, and it is the hybrid nature of tone that marks this part of the Himalaya as noteworthy. The seventeen-language sample (in Table 6) in this study largely represents the major sub-groupings of Sino-Tibetan. ${ }^{7}$ 
Table 6. Language Sample

\begin{tabular}{|c|c|c|}
\hline Language & Sub-Grouping & Description Source \\
\hline Burmese & Lolo-Burmese & Matisoff (1999); Green (2004) \\
\hline Cantonese & Sinitic & $\begin{array}{l}\text { Bauer and Matthews (2003); God- } \\
\text { dard (2005) }\end{array}$ \\
\hline Dege Tib. & Bodish & Häsler (1999) \\
\hline Dolakha Newar & Himalayish & Genetti (1994) \\
\hline Dulong & Nungish & LaPolla (2003) \\
\hline Garo & Brahmaputran & Burling (2003) \\
\hline Kayah-Li & Karenic & Solnit (1997) \\
\hline Kham & $\begin{array}{l}\text { [Remnant] Hima- } \\
\text { layish }\end{array}$ & David Watters (2002) \\
\hline Kinnauri & [West] Himalayish & Sharma (1988) \\
\hline Kyirong Tib. & Bodish & Huber (2002) \\
\hline Lahu & Lolo-Burmese & Matisoff (1973a; 2003) \\
\hline Limbu & Kiranti & van Driem (1987) \\
\hline Manange & Bodish, Tamangic & Hildebrandt $2003 ; 2005$ \\
\hline Mandarin & Sinitic & $\begin{array}{l}\text { Li \& Thompson (1981); Duanmu } \\
\text { (2000) }\end{array}$ \\
\hline Meithei & Kuki-Chin & Chelliah (1997) \\
\hline Qiang & Qiangic & LaPolla and Huang (2003) \\
\hline $\mathrm{Wu}$ & Sinitic & Zee and $\mathrm{Xu} 2003$ \\
\hline
\end{tabular}

These languages are plotted in Map 2, along with a rough trajectory of the Brahmpatura River (dashed line).

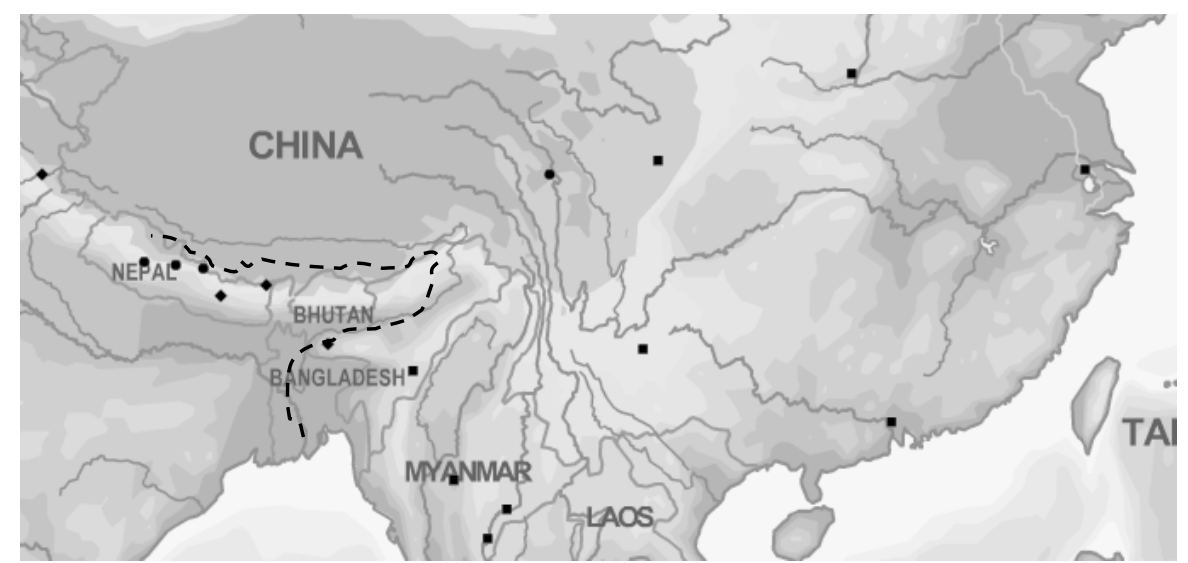

Map 2. Map of Seventeen Sino-Tibetan Languages 
There is some oversampling within both sub-families, and while the Sinitic languages appear under-represented here, further sub-divisions within Sinitic are debated. In addition, the Bodish and Himalayish languages in the sample represent different further internal divisions. ${ }^{8}$

The languages in the sample are further divided into three spheres. The Sinosphere and the Indosphere were proposed by Matisoff (1991: 485486) as defined by a combination of cultural and linguistic features, and is further characterized here with geographic delineations provided by me, following Bickel and Nichols (2003).

(4) Three spheres

A. The Sinosphere (Burmese, Cantonese, Dulong, Kayah Li, Lahu, Mandarin, Meithei, Qiang, Wu)

The Sinosphere is geographically east of the Brahmaputra river. Culturally it has been defined by Matisoff as a zone of early Han influence, extended ricebased agricultural practices, and therefore multiple terms coding the meaning 'rice.' Linguistically, Sinospheric languages are characterized by (strict) monosyllabicity, elaborate tone systems, and/or rudimentary morphology (Matisoff 1991: 485). The Sinospheric languages in this study are represented by square symbols (ם).

\section{B. The Indosphere (Dolakha Newar, Kinnauri, Garo, Limbu)}

Geographically, Indospheric languages lie mainly west of the Brahmaputra River, also mainly westward of the Tibetan Plateau. Culturally, this area is defined by the presence of a "Kingship" ideas and Hindu-Buddhist religious traditions, and by the presence of Devanagri-based writing systems (Matisoff 1991: 485). Linguistically, Indospheric languages are characterized by a-tonal (or incipiently tonal) phonology, with polysyllabicity and more complex morphology. They are represented by diamond symbols ( ).

\section{The Buffer Zone (Dege Tibetan, Kham, Kyirong Tibetan, Manange)}

Geographically, the Buffer Zone in this account is based mainly along the Tibetan Plateau. Culturally, elements of both Indospheric and Sinospheric practices and traditions are simultaneously present. Linguistically, a 'Buffer Zone' is a zone of deviation from a typological profile that otherwise consistently marks a larger area, or, languages that represent "a hybridization of the two opposite patterns of their neighbors in either direction" (Stilo 2005: 38). Matisoff (1999), while not explicitly postulating a typological 'Buffer Zone', indicates that the tonal profiles of ST languages are divergent enough to be considered in areal as well as genealogical perspective. While some prosodic properties, like overall phonological coherence of inflectional morphemes, do not significantly distinguish buffer zone languages from Indospheric and Sinospheric, others do (e.g. the presence/absence of tone and individual formative phonological dependen- 
cies) (Bickel and Hildebrandt 2005). Geographically, Buffer Zone languages are also hybrid, being largely contained within the Tibetan Plateau, but stretching in some cases east of the Brahmaputra River (e.g. Dege Tibetan). These languages are represented by circle symbols $(\bullet)$

It should be noted that the spheric sub-divisions and the location of individual languages within specific zones are not unproblematic, particularly for languages like Garo and Meithei, which geographically straddle the Brahmaputra area or are located along the Himalayan spine. With these three proposed spheres in mind, I investigate two questions: First, does the nature/type of tone system significantly identify the sampled languages as members of these three spheres? Second, does the contrastive TBU significantly identify the sampled languages as sphere members?

\subsection{Tone types}

The first study concerns the nature of tone systems in the sample. The tone systems here are divided into three types, described in Table $7 .{ }^{9}$

Table 7. Tone System Types (Languages)

\begin{tabular}{lll}
\hline No tone & The languages are a-tonal & $\begin{array}{l}\text { Dolakha Newar, Garo } \\
\text { Kinnauri, Limbu, Qiang }\end{array}$ \\
\hline Amalgam & $\begin{array}{l}\text { For at least half of the tones, the phone- } \\
\text { tic correlates include } \mathrm{F}_{0} \text { and } \text { phonation } \\
\text { differences. The number of contrastive } \\
\text { tones is often four or fewer } \\
\text { Tone is (almost) entirely a function of } \mathrm{F}_{0} \\
\text { distinctions. If there is an additional } \\
\text { parameter, it applies to only one tone. }\end{array}$ & $\begin{array}{l}\text { Burmese } \\
\text { tan, Kham, Kyirong } \\
\text { Tibetan, Manange }\end{array}$ \\
$\begin{array}{l}\text { The number of tones is often greater than } \\
\text { Pure }\end{array}$ & $\begin{array}{l}\text { Kayah-Li, Lahu, Man- } \\
\text { darin, Meithei, Wu }\end{array}$ \\
&
\end{tabular}


The findings of a cross-tabulation testing whether the hypothesized categories are significant indicators of different spheres are shown in Figure 4.

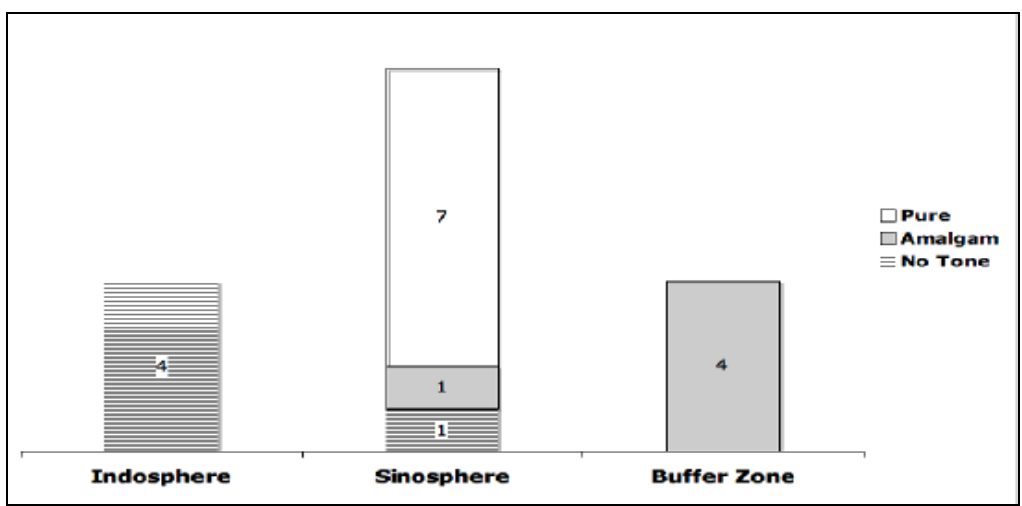

Figure 4. Tone system types across proposed spheres

The three zones are (significantly) distinct; Indospheric languages are atonal, Buffer Zone languages have amalgam systems; Sinospheric languages have mainly pure tone systems, with one case of amalgam tone (Burmese) and one case of no tone (Qiang). ${ }^{10}$

\subsection{Tone domains}

The second study investigates whether the word-level TBU significantly distinguishes Buffer Zone languages from the other spheres. With the same sphere, the TBU-types are subdivided into three types in Table 8.

Table 8. TBU Types (Languages)

\begin{tabular}{|c|c|c|}
\hline $\begin{array}{l}\text { No } \\
\text { Tone }\end{array}$ & The language is a-tonal & $\begin{array}{l}\text { Dolakha Newar, Garo, } \\
\text { Kinnauri, Limbu, Qiang }\end{array}$ \\
\hline Syllable & $\begin{array}{l}\text { The TBU is purely prosodic. This also } \\
\text { includes 'sesquisyllabic' languages, } \\
\text { where the TBU is a full syllable and a } \\
\text { reduced (/ə/) syllable }\end{array}$ & $\begin{array}{l}\text { Burmese, Cantonese, } \\
\text { Dulong, Kayah-Li, Lahu, } \\
\text { Mandarin, Wu }\end{array}$ \\
\hline Word & $\begin{array}{l}\text { The TBU references a unit defined } \\
\text { both prosodically and morphologically }\end{array}$ & $\begin{array}{l}\text { D. Tibetan, Kham, K. } \\
\text { Tibetan, Manange, } \\
\text { Meithei }\end{array}$ \\
\hline
\end{tabular}

The findings from a second cross-tabulations are shown in Figure 5. 


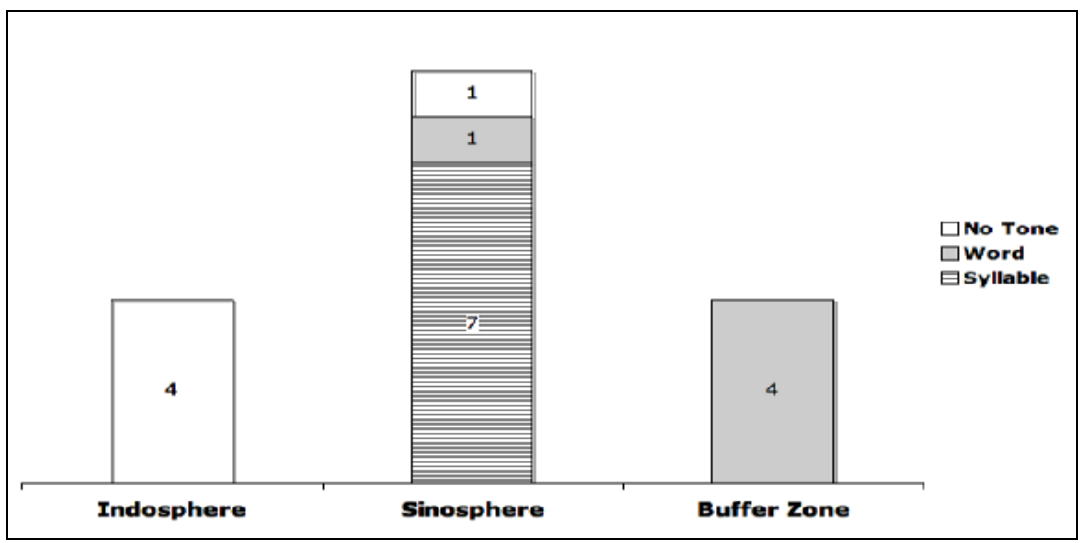

Figure 5. Tone domains across proposed spheres

Figure 5 shows that the P-word is the TBU for all Buffer Zone languages, and that the syllable is the TBU for most Sinospheric languages (except for Qiang, which is a-tonal, and Meithei, which has word-tone. ${ }^{11}$

\subsection{Implications}

The findings from these surveys indicate that Bodish languages (and Kham) are characterized by hybrid prosodic properties akin to related languages towards the west (Indosphere) and also towards the east (Sinosphere). Namely, they are tonal, but the correlates include syllable structure and segment phonation, and the domains reference morphological structure. In this way Buffer Zone languages begin to resemble Indospheric ST and Indo-European languages of the area. These findings are also reminiscent of phenomena observed in the Indo-European and Finno-Ugric languages of the Circum-Baltic "border zone", with stress patterns and polytonicity generally unattested in other European languages (Koptjevskaja-Tamm 2006: 185; Koptjevskaja-Tamm and Wälchli 2001). These findings also underscore the necessity of including Bodish languages in phonological typologies when considered in light of previous accounts, which include only Chinese as the Sino-Tibetan exemplar (e.g. Duanmu 2004) or else focus on (prosodic only) rhyme structures (e.g. Gordon 2001). 


\section{Sociolinguistic variables}

The previous sections have shown that both the nature and the domain for tonal contrasts in Bodish languages situate them in a typologically distinct position within ST, necessitating their inclusion in tonal typologies. However, the task of detailing the correlates even within a relatively small subgrouping like Bodish is challenging, due to extralinguistic variables like language contact (inter- and intra-family), gender, and education.

While these variables complicate the typologizing of Bodish tone, these details are still necessary in order to capture the facts that contribute to their properties and the typological proposals. In this section I again provide a survey of studies of such socio-cultural factors.

\subsection{Tone and gender in Tamang}

Mazaudon (1973: 82) notes that the breathy vowel quality characteristic of two of the Tamang tones is easier to perceive in males' speech than in females'. For the same elicited words, there is a robust breathiness present in the male speech, and this breathiness is replaced by a less salient form of onset aspiration for females. This makes morpheme differentiation across tones difficult, as the functional load for vowel phonation in Tamang is relatively high and plays a rather large role in lexical disambiguation. This production of tone by female Tamang speakers also parallels the system in Manange, where onset consonant aspiration plays a (secondary) role, and vowel phonation plays no role.

\subsection{Gurung regional dialects, gender differences, and tonal correlates}

In a survey of three Gurung dialects spoken in Lamjung and Kaski districts (Nepal), Glover and Landon (1980) found a degree of both lexical variation and sound shifts (i.e. phoneme alternations or replacements) across village speech communities. They also found that Ghanpokhara Gurung in Kaski District shows no evidence of breathy phonation on vowels, unlike what typifies the tone of other dialects. Rather breathiness has been replaced by aspiration when the word begins with a voiceless stop (e.g. other dialects bali vs. Ghanpokhra $p^{h} a l i$ 'foot'; other dialects tini vs. Ghanpokhra $t^{h}$ ina 'sun'). In still other Kaski dialects, there is the absence of vowel 
breathiness without the co-occurrence of voiceless aspiration (e.g. both gri and gri 'one' in different dialects).

Two descriptions by Wilbur (2004) and Hünlich (2006) focus on the phonetics and phonology of Gurung spoken in two villages of the Manang district (Thancok/Timang and Nace), east and north of Lamjung (henceforth Manang-Gurung). Wilbur notes that about $25 \%$ of the vocabulary between Ghachok and Manang-Gurung varieties are segmentally different. Their findings also suggest that tonal correlates in Manang-Gurung correspond more with those found in Manange than with other Gurung varieties. Hünlich observed that while there are some words with (marginally) breathy phonation on vowels (e.g. [mì] 'person'), most words have modal vowels, regardless of pitch-melody. In addition, one speaker's breathy vowel phonation may be realized as modal by another speaker, suggesting that phonation type is not always stable or are perhaps subject to dialectal variation as well.

Another interesting discovery is that the pitch-melody patterns from different speakers from the same community are different. Figure 6 displays lines linking mean starting, mid-point and end-point $F_{0}$ values for a set of words from the four tones, produced by a female and male Gurung speaker. Both speakers are from Nace Village, Manang, and are of approximately the same age.

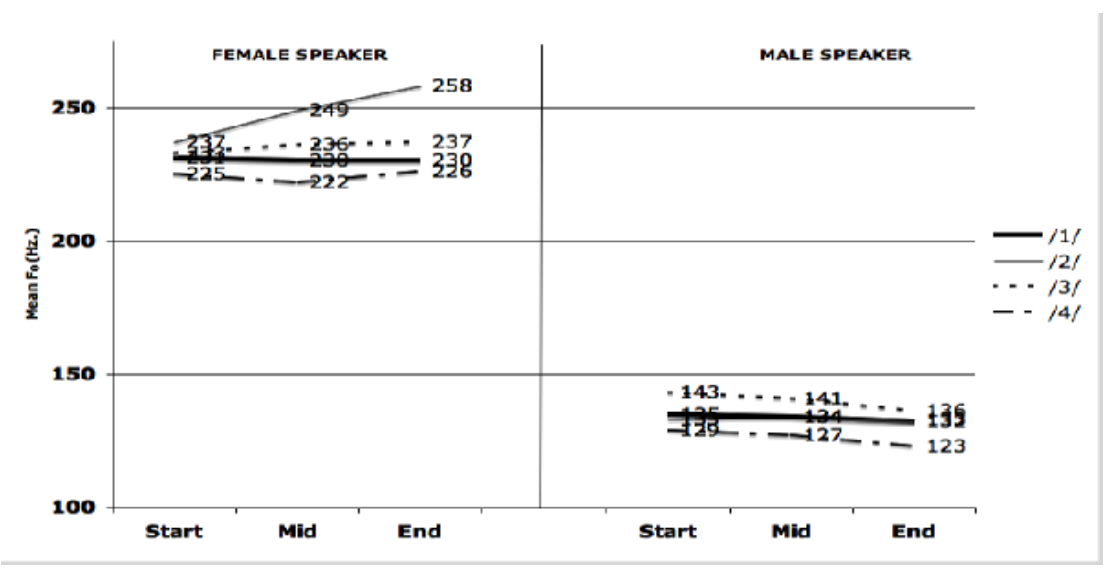

Figure 6. Mean $\mathrm{F}_{0}$ Values, Female and Male Speakers

For the male speaker (on the right side of Figure 6 ), the $F_{0}$ values significantly pattern with four (level and contour) tones. The female speaker, on the other hand, shows evidence of three tones of relatively different heights 
$(/ 1 /, / 3 /$ and $/ 4 /)$, with one tone on a rising trajectory through time $(/ 2 /)$. This difference between gender is reminiscent of observations by Mazaudon about male and female Tamang speakers, but it is different from what is found for male and female Manange speakers. Also interesting is that, despite the phonetic (acoustic) differences between the two speakers, the female perceives male's words as identical to hers; in an intelligibility test comprised of tonal minimal sets produced in a context-free setting by the male speaker, she accurately identified the different meanings.

It should be noted that Hünlich has observed that even though the $\mathrm{F}_{0}$ properties of words from Manang-Gurung speakers are qualitatively in line with the four-way distinction in Tamangic languages, there is enough $F_{0}$ variation across speakers from different villages that the patterns are not significantly coherent to the degree that they are for Manange. As such, more acoustic and perceptual investigations are necessary across the Manang-Gurung communities before a definitive statement about tone in this variety of the language can be made.

\subsection{Language contact, language use and tone in Urban Manange}

A recent study on cross-speaker phonetic and phonological tone patterns was performed with speakers from two Manange communities in Nepal (Hildebrandt 2003). One community is the traditional rural area of Manang. The other community is located in Kathmandu. In recent generations, it has become commonplace for many Mananges to migrate temporarily or permanently to the Kathmandu valley, or to lower elevations within Manang during winter, where Nepali (Indo-European) is spoken. (cf. Rogers 2004 for a historical-economic study of Manange society).

The study concerns the phonetics of tone in two Manange populations: Rural speakers, who were born or raised in Manang, had little or no formal education, and who used Manange on a regular, basis, and Urban speakers, who were born or raised in Kathmandu, who had extensive formal education, and who used Manange in more restricted and interrupted settings alongside Nepali.

The findings indicate that Urban speakers show a large-scale phonetic merger of the four tones into a two-way (high-low) opposition. In addition, the conceptualization and grouping of words into different melody groups is considerably fuzzier for them than for Rural Mananges. The $\mathrm{F}_{0}$ plots in Figures 7 and 8 illustrate this difference across the groups. 


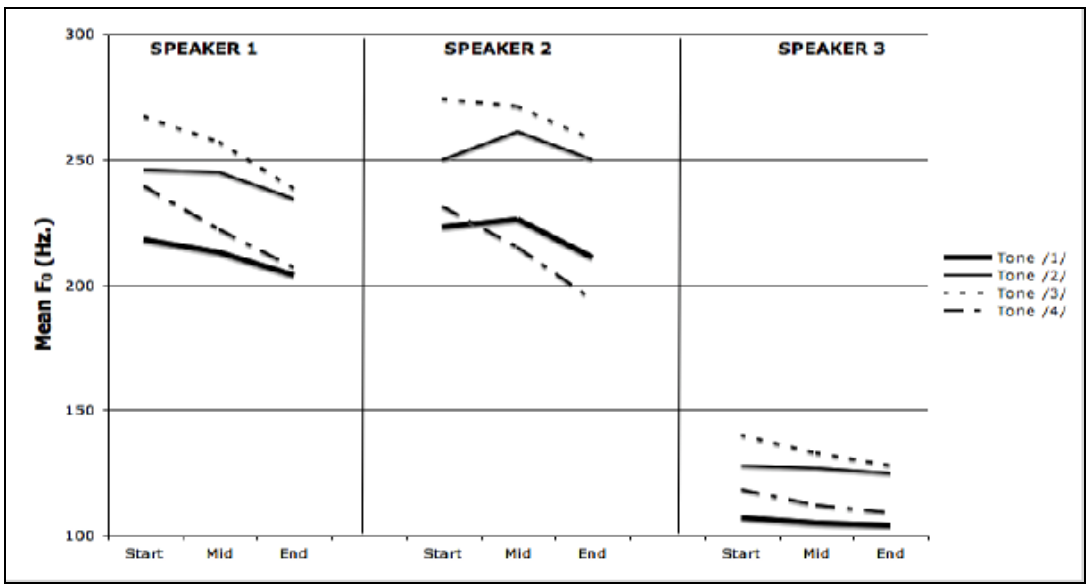

Figure 7. Mean $\mathrm{F}_{0}$ Values, Three Rural Speakers

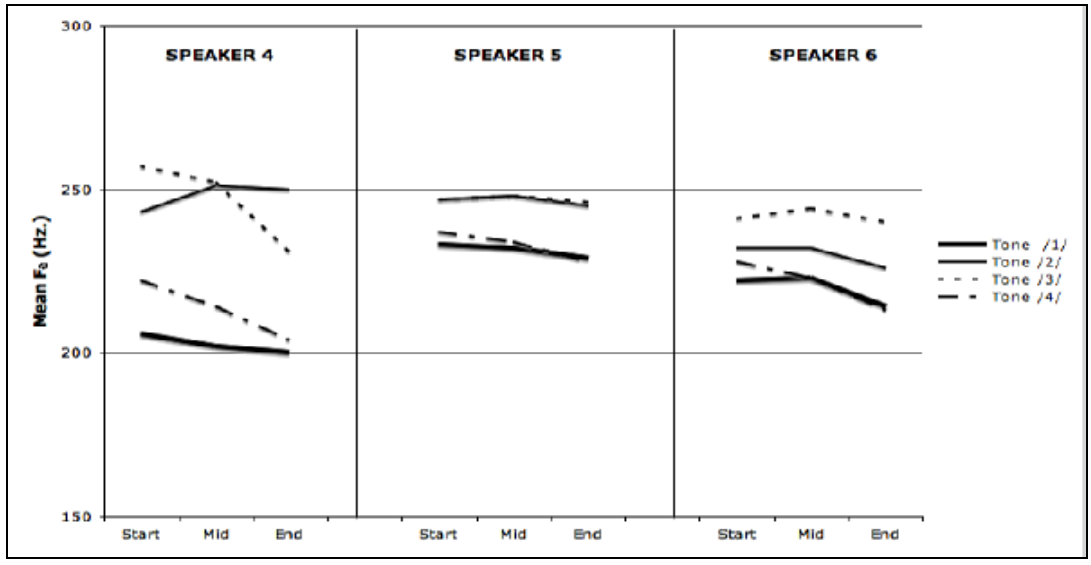

Figure 8. $\mathrm{F}_{0}$ Values Three Urban Speakers

In Figure 7, the data are in line with the four-way system documented for Manange (Mazaudon 1973; Hildebrandt 2003, 2004, 2005). In Figure 8, data from two of three Urban speakers of the same age group show that the same representative words display significant phonetic overlap; for two of these three speakers there is evidence for only two or three distinct pitch groupings, not four. ${ }^{12}$ Data from Speaker 4 in Figure 8 show patterns more reminiscent of the Rural speakers. Speaker 4 is also different from the other two Urban speakers in that she had no formal education and uses Manange regularly in all domains in Kathmandu.

It is not obvious that the altered tone system for Urban speakers is simply one symptom of gradual language loss (i.e. shift to Nepali) in the Kath- 
mandu community. For many Urban Mananges, the language is maintained in a situation of diglossia, used mainly in domestic, private environments, while Nepali is the language of necessity in public domains. Nevertheless, this structural result appears to be a consequence of such a maintenance scenario.

It is also not obvious that Urban Manange is borrowing anything from Nepali phonology. There is no evidence that Urban Mananges are incorporating the four-way Nepali obstruent onset voicing into their production. Rather, Hildebrandt (2003) argues that lexical frequency may play a role in determining which words evidence phonetic pitch merger and in determining the pitch properties of the emergent system.

Aside from these accounts, there is a rather disheartening lack of available information on dialectal differences across the different Bodish language speaker communities. This is especially troubling given the growing pace of language replacement in Nepal. These studies do suggest, however, that the phonological properties of a language should not be thought of as purely static in nature (synchronically and diachronically), or isolated from extra-linguistic (socio-cultural) factors.

\section{Conclusions, remaining questions and future directions}

In this paper I have demonstrated that the nature of tone in Bodish languages (and beyond) identifies these as of special typological interest. In addition, the complex cross-speaker and cross-community correlates to tone in select Bodish languages indicate that sociolinguistic variables must be further taken into account in any satisfactory and comprehensive analysis of tone in these languages.

Ultimately, this account raises more questions than it answers. For example: what other aspects of phonology (aside from tone) in these languages reveal the P-word as a valid prosodic domain? Is it valid to assume that Sinospheric languages have little evidence for prosodic domains beyond the syllable and/or foot? How do tone correlates vary across other TB language speech communities? In addition, how is tone perceived across these speech communities? These and other questions remain open topics for ongoing and future investigations. Given current scenarios of language shift, maintenance and change, the present time is crucial to attempt answers to these questions. 


\section{Notes}

1. This study was supported by different funds: a National Science Foundation Grant BNS 9729005, funding from the University of California, and funding from the German DFG grant BI 799/2. I wish to thank the volume editors Bernhard Wälchli and Matti Miestamo and two anonymous reviewers for their comments, and also the members of the Manange and Manang-Gurung communities for their ongoing assistance with my study of their languages. Any errors are my own. Abbreviations: INDEF Indefinite, LOC Locative, PTCL Particle, TOP Topic.

2. Words without a diacritic carry a mid-level tone.

3. The diacritics in Table 1 are slightly different from those used by Huber, but the facts about the tone system remain the same.

4. All maps here are generated via the Interactive Reference Tool (WALS).

5. There is often a slight falling or rise-fall pitch effect on the grammatical suffixes of bimorphemic verb roots for all tones. In disyllabics, it is more level, with a rise-fall tendency on the second syllable.

6. In some Bodish languages (e.g. Kyirong, Sherpa), prefixes are excluded from the word-level tone domain. They are toneless and do not pick up the $\mathrm{F}_{0}$ properties of the stem. Prefixes as non-cohering to the larger P-Word are found in other languages like Hungarian and German (cf. Hall 1999).

7. The Tani branch is not represented here, due to lack of available data.

8. Another motivation for including these languages here is because exhaustive prosodic data are currently available through the (Phonological) Word Domains component of the Autotyp Project (www.uni-leipzig.de/ autotyp).

9. This study is also inspired by Maddieson (2005), who surveyed tone types across 526 languages, with slightly different terminology and definitions.

10. Fisher's Exact value $=.001$, with a value of $<.05$ achieving significance

11. Fisher's Exact value $=.001$, with a value of $<.05$ achieving significance

12. Significance $($ p. $<.05)$ achieved via an ANOVA of mean starting, mid-point and ending $\mathrm{F}_{0}$ values for 400 words elicited in frame-medial context.

\section{References}

Bauer, Robert S., and Stephen Matthews

2003 Cantonese. In The Sino-Tibetan Languages, Graham Thurgood, and Randy J. LaPolla (eds.), 146-155. London: Curzon Press.

Bickel, Balthasar, and Kristine A. Hildebrandt

2005 Diversity in phonological word domains. Presentation at the 2005 Association for Linguistic Typology biannual meeting. http://www.uni-leipzig.de/ autotyp/projects/wd_dom/wd_dom.html 
Bickel, Balthasar, and Johanna Nichols

2003 Typological enclaves. Presentation at the 2003 Association for Linguistic Typology biannual meeting. http://www.unileipzig.de/ autotyp/download/enclaves@ALT5-2003BB-JN.pdf

Burling, Robbins

1992 Garo as a minimal tone language. Linguistics of the Tibeto-Burman Area 15 (5): 33-51.

2003 Garo. In The Sino-Tibetan Languages, Graham Thurgood, and Randy J. LaPolla (eds.), 487-500. London: Curzon Press.

Chelliah, Shobhana L.

1997 A Grammar of Meithei. Berlin: Mouton de Gruyter.

Duanmu, San

2000 The Phonology of Standard Chinese. Oxford: Oxford University Press.

2004 Tone and non-tone languages: An alternative to language typology and parameters. Language and Linguistics 5 (4): 891-924.

Genetti, Carol

1994 A Descriptive and Historical Account of the Dolakha Newari Dialect. (Monumenta Serindica, 24) Tokyo: Institute for the Study of Languages and Cultures of Asia and Africa.

Georg, Stefan

1996 Marphatan Thakali. (LINCOM Studies in Asian Linguistics 02) München/Newcastle: Lincom Europa.

Glover, Warren W.

1970 Gurung tone and higher levels. In Occasional Papers of the Wolfenden Society on Tibeto-Burman Linguistics iii, Austin Hale, and Kenneth I. Pike (eds.), 52-73. Urbana: University of Illinois.

Glover, Warren W., and A. K. Landon

1980 Gurung Dialects. Papers in South East Asian Linguistics 53: 29-77. (Pacific Linguistics Series A 53). Canberra: Australian National University.

Glover, Warren W., Jesse. R. Glover, and D. B. Gurung

1977 Gurung-Nepali-English Dictionary, with English-Gurung and Nepali-Gurung Indexes. (Pacific Linguistics Series C, no. 51) Canberra: Australian National University.

Goddard, Cliff

2005 The languages of East and Southeast Asia: An Introduction. Oxford: Oxford University Press.

Gordon, Matthew

2001 A typology of contour tone restrictions. Studies in Language 25 (3): $423-462$.

Green, Antony R. 
2004 Word, foot, and syllable structure in Burmese. Rutgers Optimality Archive ROA 115.

Hale, Austin

1973 Clause, Sentence and Discourse Patterns in Selected Languages of Nepal: Part IV, Word Lists. Norman, OK: Summer Institute of Linguistics.

Hall, T. Alan

1999 The phonological word: A review. In Studies on the Phonological Word, T. Alan Hall, and Ursula Kleinhenz (eds.), 1-22. Amsterdam/Philadelphia: Benjamins.

Hall, T. Alan, and Kristine A. Hildebrandt

forthcoming Phonological and Morphological Domains in Kyirong Tibetan. Linguistics.

Häsler, Katrin

1999 A grammar of the Tibetan Dege (Sde dge) Dialect. Ph.D. diss., Universität Bern.

Hildebrandt, Kristine A.

2003 Manange Tone: Scenarios of Retention and Loss in Two Communities. Ph.D. diss., Department of Linguistics, University of California Santa Barbara.

2004 A grammar and dictionary of the Manange language. In TibetoBurman Languages of Nepal: Manange and Sherpa, Carol Genetti (ed.), 2-189. Canberra: Pacific Linguistics.

2005 A phonetic analysis of Manange segmental and suprasegmental properties. Linguistics of the Tibeto-Burman Area 28 (1): 1-36.

Honda, Isao

2002 Seke phonology: A comparative study of three Seke dialects. Linguistics of the Tibeto-Burman Area 25 (1): 191-210.

Huber, Brigitte

2002 The Lende Subdialect of Kyirong Tibetan (Grammar and Glossary). Ph.D diss., Universität Bern.

Hünlich, David

2006 Tone in Manang Gurung: Intelligibility test and acoustic analysis. Ms.

Kelly, Barbara

2004 A grammar and glossary of the Sherpa language. In Tibeto-Burman Languages of Nepal: Manange and Sherpa, Carol Genetti (ed.), 193-324. Canberra: Pacific Linguistics.

Koptjevskaja-Tamm, Maria

2006 The circle that won't come full: Two potential isoglosses in the Circum-Baltic area. In Linguistic Areas, Yaron Matras, April McMahon, and Nigel Vincent (eds.), 182-226. Basingstoke, U.K. and New York: Palgrave Macmillan. 
Koptjevskaja-Tamm, Maria, and Bernhard Wächli

2001 The Circum-Baltic languages: An areal-typological approach. In The Circum-Baltic Languages, Östen Dahl, and Maria KoptjevskajaTamm (eds.), 615-750. Amsterdam/Philadelphia: John Benjamins.

LaPolla, Randy J.

2003 Dulong. In The Sino-Tibetan Languages, Graham Thurgood, and Randy J. LaPolla (eds.), 674-682. London: Curzon Press.

LaPolla, Randy J., and Chenglong Huang

2003 A Grammar of Qiang, with Annotated Texts and Glossary. (Mouton Grammar Library 31.). Berlin: Mouton de Gruyter.

Li, Charles N, and Sandra A. Thompson

1981 Mandarin Chinese: A Functional Reference Grammar. Berkeley, CA: University of California Press.

Maddieson, Ian

2005 Tone. In The World Atlas of Language Structures, Martin Haspelmath, Matthew S. Dryer, David Gil, and Bernard Comrie (eds.), 5861. Oxford, UK: Oxford University Press.

Matisoff, James A.

1973a The grammar of Lahu. Berkeley, CA: University of California Press.

1973b Tonogenesis in Southeast Asia. In Consonant Types and Tone, Larry M. Hyman (ed.), 73-95. (Southern California Occasional Papers in Linguistics No. 1.)

1995 Tone, intonation and sound symbolism in Lahu: Loading the syllable canon. Linguistics of the Tibeto-Burman Area 12 (2): 147-163.

1999 Tibeto-Burman tonology in an areal context. In Proceedings of the Symposium: Cross-linguistic Studies of Tonal Phenomena Tonogenesis, Typology, and Related Topics, Shigeki Kaji (ed.), 3-32. Tokyo: Institute for the study of Languages and Cultures of Asia and Africa, Tokyo University of Foreign Studies.

2003 Lahu. In The Sino-Tibetan Languages, Graham Thurgood, and Randy J. LaPolla (eds.), 208-220. London: Curzon Press.

Mazaudon, Martine

1973 Phonologie Tamang: Étude Phonologique du Dialecte Tamang de Risiangku (Langue Tibeto-Burmane du Nepal). Paris: SELAF.

1977 Tibeto-Burman tonogenetics. Linguistics of the Tibeto-Burman Area 3 (2): 1-123.

1978 Consonantal mutation and tonal split in the Tamang sub-family of Tibeto-Burman. Kailash 7 (3): 157-179.

Noonan, Michael

2003 Nar-Phu. In The Sino-Tibetan Languages, Graham Thurgood, and Randy J. LaPolla (eds.), 336-352. London: Curzon Press.

Rogers, Clint

2004 Secrets of Manang. Kathmandu, Nepal: Mandala Publications. 
Sharma, D. D.

1988 A Descriptive Grammar of Kinnauri. Delhi: Mittal.

Solnit, David

1997 Eastern Kayah Li: Grammar, Texts, Glossary. Honolulu: University of Hawaii Press.

Sprigg, R. K.

1997 A tonal analysis of Gurung, with separate systems for register and contour pitch features. Bulletin of the Society for Oriental and African Studies 60 (3): 448-454.

Stilo, Donald L.

2005 Iranian as buffer zone between the universal typologies of Turkic and Semitic. In Linguistic Convergence and Areal Diffusion: Case Studies From Iranian, Semitic and Turkic, Éva Ágnes Csató, Bo Isaksvan Driem, George son, and Carina Jahani (eds.), 35-64. London: Routledge Curzon.

1987 A Grammar of Limbu. Berlin: Mouton de Gruyter.

Watters, David

2002 A Grammar of Kham. Cambridge: Cambridge University Press.

Watters, Stephen

1999 Tonal contrasts in Sherpa. In Topics in Nepalese Linguistics, Yogendra P. Yadava, and Warren W. Glover (eds.), 54-77. Kamaladi Kathmandu: Royal Nepal Academy.

2002 The sounds and tones of five Tibetan languages of the Himalayan region. Linguistics of the Tibeto-Burman Area 25 (1): 1-66.

Wilbur, Joshua

2004 Observations on Varieties of Gurung spoken in the Gyalsumdo Cultural Sphere of Manang. Paper given at the $25^{\text {th }}$ Annual Linguistic Society of Nepal Meeting, Kathmandu Nepal.

Yip, Moira

2002 Tone. Cambridge: Cambridge University Press.

Zee, Eric, and Liejiong Xu

2003 Shanghai. In The Sino-Tibetan Languages, Graham Thurgood, and Randy J. LaPolla (eds.), 131-145. London: Curzon Press. 